\title{
Dynamic models of immune responses: what is the ideal level of detail?
}

\author{
Juilee Thakar ${ }^{1 *}$, Mary Poss², Réka Albert ${ }^{1}$, Gráinne H Long ${ }^{1}$, Ranran Zhang ${ }^{2}$
}

* Correspondence:

jthakar@phys.psu.edu

${ }^{1}$ Center for Infectious Disease

Dynamics and Department of Physics, Pennsylvania State

University, University Park, PA 16802, USA

\begin{abstract}
Background: One of the goals of computational immunology is to facilitate the study of infectious diseases. Dynamic modeling is a powerful tool to integrate empirical data from independent sources, make novel predictions, and to foresee the gaps in the current knowledge. Dynamic models constructed to study the interactions between pathogens and hosts' immune responses have revealed key regulatory processes in the infection.
\end{abstract}

Optimum complexity and dynamic modeling: We discuss the usability of various deterministic dynamic modeling approaches to study the progression of infectious diseases. The complexity of these models is dependent on the number of components and the temporal resolution in the model. We comment on the specific use of simple and complex models in the study of the progression of infectious diseases

Conclusions: Models of sub-systems or simplified immune response can be used to hypothesize phenomena of host-pathogen interactions and to estimate rates and parameters. Nevertheless, to study the pathogenesis of an infection we need to develop models describing the dynamics of the immune components involved in the progression of the disease. Incorporation of the large number and variety of immune processes involved in pathogenesis requires tradeoffs in modeling.

\section{Background}

Immune responses encompass a large range of temporal- (millisecond to days) and spatial (molecular to whole body) scales. It is increasingly recognized that intuitive arguments are not sufficient to make sense of this complexity. As an alternative, dynamic models are more and more frequently used to synthesize and complement empirical studies. Many dynamic models lead to valuable insights and predictions. For example, early dynamic models of infections provide a significant insight into the progression of AIDS [1,2].

The specific goal of a dynamic model of an infection may be to estimate certain parameters [3], to test competing hypotheses that can explain a set of observations $[4,5]$ or to study the interplay between a pathogen and a host which can result in a progressive infection [6,7]. Immunological models consist of components representing immunological entities such as cells and cytokines, equations representing how the relationship between components changes their status, and parameters (e.g. rate constants) plugged into the equations which define the strength and timing of the

(C) 2010 Thakar et al; licensee BioMed Central Ltd. This is an Open Access article distributed under the terms of the Creative Commons Attribution License (http://creativecommons.org/licenses/by/2.0), which permits unrestricted use, distribution, and reproduction in any medium, provided the original work is properly cited. 
relationships. Among the various mathematical frameworks employed by dynamic models (see Table 1), the deterministic (noise-free) framework is most frequently used at the cellular level. As the number of components included in a model increases, so does the number of parameters, and the value of most parameters tends to be unknown. Stereotypical models based on a simplified description that ignores the details of specific systems consist of few components, few kinetic rate constants and avoid the artifacts that might emerge from complex, parameter-rich models. Models of HIV infections developed upon the above principles have pioneered the field $[1,2]$. Nevertheless, models tracking a larger number of immune components are often desirable when studying the progression of an infection or disease.

Given our need to study the dynamics of immune responses to infection across different biological scales, and the limitations posed by the current state of empirical data, here we discuss the applications of simple versus complex models, and explore the use of discrete dynamic models. Excellent reviews of mathematical modeling in

Table 1 Overview of dynamic modeling methods

\begin{tabular}{|c|c|c|c|c|}
\hline $\begin{array}{l}\text { Dynamic modeling } \\
\text { method }\end{array}$ & Granularity & $\begin{array}{l}\text { Examples in } \\
\text { immunology }\end{array}$ & Pros and cons & Refs. \\
\hline $\begin{array}{l}\text { Discrete dynamic } \\
\text { models }\end{array}$ & $\begin{array}{l}\text { Discrete time and } \\
\text { discrete (abstract) } \\
\text { state }\end{array}$ & $\begin{array}{l}\text { Modeling of Bordetella } \\
\text { infection pathogenesis, } \mathrm{T} \\
\text { cell receptor signaling }\end{array}$ & $\begin{array}{l}\text { Can deal with many } \\
\text { components but the simple } \\
\text { state description cannot } \\
\text { replicate continuous } \\
\text { variation of immune } \\
\text { components. }\end{array}$ & {$[6,44-47]$} \\
\hline $\begin{array}{l}\text { Continuous-discrete } \\
\text { hybrid models (e.g. } \\
\text { piecewise linear } \\
\text { differential } \\
\text { equations) }\end{array}$ & $\begin{array}{l}\text { Combination of } \\
\text { discrete and } \\
\text { continuous state, } \\
\text { continuous time }\end{array}$ & $\begin{array}{l}\text { Modeling of infection } \\
\text { pathogenesis and } \\
\text { pathogen time-courses }\end{array}$ & $\begin{array}{l}\text { The number of components } \\
\text { that can be modeled is } \\
\text { smaller than in discrete } \\
\text { models because of the } \\
\text { increase in the number of } \\
\text { parameters. The state of the } \\
\text { variables may not be } \\
\text { directly comparable with } \\
\text { experimental measurements. } \\
\text { Although there are few } \\
\text { parameters per component, } \\
\text { parameter estimation } \\
\text { becomes an issue for large } \\
\text { systems. }\end{array}$ & {$[7,36]$} \\
\hline $\begin{array}{l}\text { Differential } \\
\text { equations }\end{array}$ & $\begin{array}{l}\text { Continuous time } \\
\text { and state }\end{array}$ & $\begin{array}{l}\text { SIR (Susceptible Infectious } \\
\text { and Recovered) models } \\
\text { of target cells and } \\
\text { pathogens, T cell } \\
\text { differentiation }\end{array}$ & $\begin{array}{l}\text { The variables of the model } \\
\text { can reproduce the } \\
\text { experimentally observed } \\
\text { concentrations. Insufficient } \\
\text { data to inform the } \\
\text { functional forms and } \\
\text { parameter values can limit } \\
\text { the use of this method. Less } \\
\text { scalable than discrete } \\
\text { approaches. }\end{array}$ & {$[11,13,20]$} \\
\hline $\begin{array}{l}\text { Finite state } \\
\text { automata (e.g. } \\
\text { agent-based } \\
\text { models) }\end{array}$ & $\begin{array}{l}\text { Discrete states } \\
\text { (abstraction of cell } \\
\text { state), discrete } \\
\text { space and } \\
\text { continuous time }\end{array}$ & $\begin{array}{l}\text { Cell to cell } \\
\text { communications }\end{array}$ & $\begin{array}{l}\text { Simplified way to simulate } \\
\text { spatial aspects. Can handle a } \\
\text { few immune components in } \\
\text { detail. Computationally } \\
\text { expensive. }\end{array}$ & [48-50] \\
\hline $\begin{array}{l}\text { Partial differential } \\
\text { equations }\end{array}$ & $\begin{array}{l}\text { Continuous time, } \\
\text { state and space }\end{array}$ & $\begin{array}{l}\text { Transport of cells across } \\
\text { vascular membranes }\end{array}$ & $\begin{array}{l}\text { Appropriate to model a few } \\
\text { immune components in } \\
\text { detail. Computationally } \\
\text { expensive and the } \\
\text { determination of parameters } \\
\text { is rather difficult. }\end{array}$ & {$[51,52]$} \\
\hline
\end{tabular}


immunology [8] and of modeling multi-scale interactions $[9,10]$ have already been published.

\section{Discussion}

\section{Models of sub-systems or simplified immune response}

Models can be kept relatively simple by detailing a few chosen processes and abstracting others. The number of components that need to be included in the model is reduced by focusing on a sub-system such as $\mathrm{T}$ cell expansion or the innate immune response, or by abstracting the immune response.

Dynamic models focusing on sub-systems of the immune response can be used to estimate specific parameters when appropriate empirical data is available. For example, mathematical models of $\mathrm{T}$ cell dynamics can be used to estimate $\mathrm{T}$ cell decay, production rates [11], killing rates [12], and the fate of recently produced T cells [13]. Such parameter estimates assist in the estimation of the in vivo basic reproduction number $\left(\mathrm{R}_{0}\right)$ of viral infections. They are also useful for studying the efficacy of treatment for viral infections such as HIV $[14,15]$. Models revealing the differences in $\mathrm{T}$ cell dynamics of mice and humans [16] are critical in extending the empirical observations from mice to humans. Models tracking the dynamics of virus infection of host cells and cellular innate response, for example type I Interferon, predict the rates of target cell depletion in equine influenza virus infections [17].

Several dynamic models that simplify the immune response characterize the pathogen behavior in detail. Thus they can be used to determine the optimal conditions for within-host survival of a pathogen. For instance, the limited availability of red blood cells (resource limitation) can explain the early dynamics of malaria [4]. Similar models also reveal the pathogen-induced constraints leading to acute or persistent infections [18]. Although these models are based on assumptions such as correlation between virulence and growth rate of the pathogen $[18,19]$, they give important insight into pathogenesis.

\section{Models of infection pathogenesis}

The complexity of the models increases when they aim to capture multiple components of the immune response, which can include interactions between pathogen and host factors and the subsequent generation of specific antibody and $\mathrm{T}$ cell responses. The choice of mathematical description is critical in such instances due to the intricacies it can add or simplify. One example is a quantitative model constructed to simulate the immune response to infections by Mycobacterium tuberculosis (Mtb) [20,21] that tracks the dynamics of resident macrophages, immature dendritic cells, infected macrophages and mature dendritic cells. The dynamic causality in this model is approximated by mass-action and Michaelis-Menten kinetics. Since there are quantitative estimates available for Mtb (see table 4 in $[20,21]$ ), the model can parameterize the continuous change of immune components as a function of time. The model reveals specific parameters defining the dynamics of the host's immune processes that are important in persistent and acute infections. The simulated dynamics are validated by nonhuman primate data consisting of necropsies of Mtb infected animals [22].

In the absence of quantitative and mechanistic information, but having assembled a causal interaction network of the intra-cellular and cellular players elucidated by 
immunologists, a simpler qualitative/semi-qualitative formulation without or with only a few parameters can be followed. This discrete dynamic approach is supported by the observations that regulatory networks maintain their function even when faced with fluctuations in components and reaction rates [23-31]. Various discrete dynamic frameworks including Boolean networks [32], finite dynamical systems [33], difference equations [34], and Petri nets [35] have been used in modeling biological systems. Particularly, Boolean network models assume that each component has two qualitative states (e.g. active and inactive) and reproduce a sequence of switching events instead of modeling exact time courses. The active qualitative state can be interpreted as the concentration of an immune component that can induce downstream signaling. Such network models, tracking the dynamics of more than 30 immune components including various cytokines and cells, have been constructed for two Bordetella pathogens [6,7], for which few quantitative parameters have been determined. These models reproduce the qualitative features, such as the number of peaks, of the experimental time-courses of various immune components such as neutrophils and dominant cytokines.

Continuous-discrete hybrid models $[7,36,37]$ are also developed with the aim to improve the representation of time while retaining the simplicity of switching functions. These hybrid models have a relatively small number of parameters, such as activation thresholds and decay rates, which are at a higher, more coarse-grained level than the kinetics of elementary reactions. A hybrid Bordetella model [7] reveals that many parameter combinations are compatible with the existing experimental knowledge on the pathogenesis. The distribution of the parameter values for each immune component in the model tells us about its role in the pathogenesis. Recent experimental measurements validate the IL4 time-course predicted by the model [Pathak, A. K., Creppage, K. E., Werner, J. R., Cattadori, I. M., "Immune regulation of a chronic bacterial infection and consequences for pathogen transmission", submitted].

Since the immune responses involve interactions at the site of infection, the maturation of $\mathrm{T}$ and $\mathrm{B}$ cells in the lymph nodes and the transport of cells through blood, capturing spatial dynamics may be critical for the success of a model. Approximations at various levels of detail are available that allow for the inclusion of some spatial information in the form of spatial compartments, coarse grids or reaction-diffusion processes. For example, the follow-up models of Mtb and Bordetellae [7,20] define two compartments, the site of infection (the lung) and the site of $\mathrm{T}$ cell differentiation (lymph node). A more detailed approach used by Gammack et. al. [38,39] describes granuloma formation in Mtb infections with a reaction-diffusion model using partial differential equations and the movement of innate immune cells toward a focal point of Mtb infection with a coarse-grid spatial formulation.

\section{Pros and cons of qualitative and quantitative approaches}

The decision to use qualitative or quantitative models is based on the density of observations over time, the number of molecular or cellular players participating in a particular process and the connectivity of the regulatory network formed by these players. We note that both approaches necessitate knowledge of the causal or interaction network among components. Missing data and within-lab variations caused by the use of different experimental systems can introduce uncertainty in the determination of 
causal relationships; this issue is dealt with by the techniques of reverse engineering [40]. Observations taken at many time-points minimize the uncertainty about the behavior between the observations. The availability of frequent measurements for all or almost all the immune components one wants to model facilitates the use of quantitative modeling. The unavailability of such data guides us to use qualitative models which will inform us about the sequence of events and ultimate outcomes rather than trying to interpolate between the existing sparse observations. The assumption of switch-like regulatory relationships underlying qualitative models is a good approximation if the functional form of the regulatory relationship is sigmoidal.

Qualitative and quantitative approaches detail the immune interactions at different levels. Generally speaking, quantitative models give a detailed description of a relatively small number of interactions whereas qualitative models incorporate more interactions but have fewer kinetic details. Quantitative models offer predictions of kinetic parameters and of how the system will behave at a given instance. Qualitative models predict the response to knock-out or over-expression of components. An effective strategy to bridge these two approaches can be to iteratively refine qualitative models as more quantitative information becomes available through incorporation of more states, using a continuous-discrete hybrid formalism, or a fully quantitative description of an important sub-system.

Quantitative models require substantial prior knowledge and the interactions that require parameterization in these models have not yet been quantitatively characterized for most of the infections. The assumptions and estimations necessary to give values for the parameters may introduce unwanted artifacts in the model, reducing its usefulness. Since many molecular and cellular players of the immune cascades $[41,42]$ are available for a range of infectious diseases, along with the outcomes of pathogen manipulation experiments, qualitative models can be constructed for less studied infectious diseases giving us insight about the dynamic interplay arising from the complex multi-scale interactions. Qualitative models also lose their simplicity and usefulness if the number of components and interactions included in the network is too large since that dramatically increases the system's dynamic repertoire. Various network simplification methods are available which reduce the number of components, for instance based on shortening long linear paths or collapsing alternative paths between a pair of nodes [43].

\section{Conclusion}

The simple models developed to study parts of the immune system decipher parameters that reveal the regulation of immune responses and allow us to extrapolate the observations from experimental hosts to the natural hosts. The models developed to test the evolutionary fitness of pathogens reveal fundamental characteristics of the host-pathogen interactions and give useful insight into the pathogenesis of the infections. Among the models which aim to describe most of the immune components important in the pathogenesis, we show that both qualitative and quantitative models can be used effectively to study the progression of the infections. 
http://www.cidd.psu.edu/calendar/workshops/multi-scale-modeling-of-immune-responses. JT is thankful to the Cancer Research Institute for a postdoctoral fellowship. We are also thankful to the three anonymous reviewers whose comments made this manuscript better in many ways.

\section{Author details}

${ }^{1}$ Center for Infectious Disease Dynamics and Department of Physics, Pennsylvania State University, University Park, PA 16802, USA. ${ }^{2}$ Penn State Hershey Cancer Institute, Pennsylvania State University, College of Medicine, Hershey, PA 17033 USA.

Received: 28 June 2010 Accepted: 20 August 2010 Published: 20 August 2010

\section{References}

1. Nowak MA, Anderson RM, McLean AR, Wolfs TF, Goudsmit J, May RM: Antigenic diversity thresholds and the development of AIDS. Science 1991, 254:963-969.

2. Perelson AS, Kirschner DE, De Boer R: Dynamics of HIV infection of CD4+ T cells. Math Biosci 1993, 114:81-125.

3. Banga JR, Balsa-Canto E: Parameter estimation and optimal experimental design. Essays Biochem 2008, 45:195-209.

4. Antia R, Yates A, de Roode JC: The dynamics of acute malaria infections. I. Effect of the parasite's red blood cell preference. Proc Biol Sci 2008, 275:1449-1458.

5. Ganusov W, Bergstrom CT, Antia R: Within-host population dynamics and the evolution of microparasites in a heterogeneous host population. Evolution 2002, 56:213-223.

6. Thakar J, Pilione M, Kirimanjeswara G, Harvill ET, Albert R: Modeling Systems-Level Regulation of Host Immune Responses. PLoS Comput Biol 2007, 3:e109.

7. Thakar J, Saadatpour A, Harvill ET, Albert R: Constraint Based Network Model of Pathogen-Immune System Interactions. J R Soc Interface 2009.

8. Louzoun Y: The evolution of mathematical immunology. Immunol Rev 2007, 216:9-20.

9. Kirschner DE, Linderman JJ: Mathematical and computational approaches can complement experimental studies of host-pathogen interactions. Cell Microbiol 2009, 11:531-539.

10. Meier-Schellersheim M, Fraser ID, Klauschen F: Multi-scale modeling in cell biology. Wiley Interdiscip Rev Syst Biol Med 2009, 1:4-14.

11. De Boer RJ, Ganusov W, Milutinovic D, Hodgkin PD, Perelson AS: Estimating lymphocyte division and death rates from CFSE data. Bull Math Biol 2006, 68:1011-1031.

12. Ganusov W, De Boer RJ: Estimating in vivo death rates of targets due to CD8 T-cell-mediated killing. J Virol 2008, 82:11749-11757.

13. De Boer RJ, Noest AJ: T cell renewal rates, telomerase, and telomere length shortening. J Immunol 1998 , 160:5832-5837.

14. Ribeiro RM, Mohri H, Ho DD, Perelson AS: In vivo dynamics of T cell activation, proliferation, and death in HIV-1 infection: why are CD4+ but not CD8+ T cells depleted? Proc Natl Acad Sci USA 2002, 99:15572-15577.

15. De Boer RJ: Time scales of CD4+ T cell depletion in HIV infection. PLOS Med 2007, 4:e193.

16. Vrisekoop N, den Braber I, de Boer AB, Ruiter AF, Ackermans MT, van der Crabben SN, Schrijver EH, Spierenburg G, Sauerwein $\mathrm{HP}$, Hazenberg MD, et al: Sparse production but preferential incorporation of recently produced naive $T$ cells in the human peripheral pool. Proc Natl Acad Sci USA 2008, 105:6115-6120.

17. Saenz RA, Quinlivan M, Elton D, Macrae S, Blunden AS, Mumford JA, Daly JM, Digard P, Cullinane A, Grenfell BT, et al: Dynamics of influenza virus infection and pathology. J Virol 84:3974-3983.

18. Antia R, Koella JC, Perrot V: Models of the within-host dynamics of persistent mycobacterial infections. Proc Biol Sci $1996,263: 257-263$.

19. Bonhoeffer $S$, Barbour AD, De Boer RJ: Procedures for reliable estimation of viral fitness from time-series data. Proc Biol Sci 2002, 269:1887-1893.

20. Marino S, Kirschner DE: The human immune response to Mycobacterium tuberculosis in lung and lymph node. $J$ Theor Biol 2004, 227:463-486.

21. Wigginton JE, Kirschner D: A model to predict cell-mediated immune regulatory mechanisms during human infection with Mycobacterium tuberculosis. J Immunol 2001, 166:1951-1967.

22. Marino S, Pawar S, Fuller CL, Reinhart TA, Flynn JL, Kirschner DE: Dendritic cell trafficking and antigen presentation in the human immune response to Mycobacterium tuberculosis. J Immunol 2004, 173:494-506.

23. Alon U, Surette MG, Barkai N, Leibler S: Robustness in bacterial chemotaxis. Nature 1999, 397:168-171.

24. Conant GC, Wagner A: Duplicate genes and robustness to transient gene knock-downs in Caenorhabditis elegans. Proc Biol Sci 2004, 271:89-96.

25. Csete M, Doyle J: Bow ties, metabolism and disease. Trends Biotechnol 2004, 22:446-450.

26. Eldar A, Dorfman R, Weiss D, Ashe H, Shilo BZ, Barkai N: Robustness of the BMP morphogen gradient in Drosophila embryonic patterning. Nature 2002, 419:304-308.

27. von Dassow G, Meir E, Munro EM, Odell GM: The segment polarity network is a robust developmental module. Nature 2000, 406:188-192.

28. Conant GC, Wagner A: Duplicate genes and robustness to transient gene knock-downs in Caenorhabditis elegans. Proc R Soc Lond B Biol Sci 2004, 271:89-96.

29. Csete M, Doyle J: Bow ties, metabolism and disease. Trends in Biotechnology 2004, 22:446-450.

30. Fomekong-Nanfack Y, Postma M, Kaandorp JA: Inferring Drosophila gap gene regulatory network: a parameter sensitivity and perturbation analysis. BMC Syst Biol 2009, 3:94.

31. Alvarez-Buylla ER, Chaos A, Aldana M, Benitez M, Cortes-Poza Y, Espinosa-Soto C, Hartasanchez DA, Lotto RB, Malkin D, Escalera Santos GJ, Padilla-Longoria P: Floral morphogenesis: stochastic explorations of a gene network epigenetic landscape. PLoS One 2008, 3:e3626.

32. Kauffman SA: Metabolic stability and epigenesis in randomly constructed genetic nets. J Theor Biol 1969, 22:437-467. 
33. Jarrah AS, Laubenbacher R: Finite Dynamical Systems: A Mathematical Framework for Computer Simulation. Mathematical Modeling, Simulation, Visualization and e-Learning Springer Berlin HeidelbergKonaté D 2007.

34. May RM: Simple mathematical models with very complicated dynamics. Nature 1976, 261:459-467.

35. Chaouiya C: Petri net modelling of biological networks. Brief Bioinform 2007, 8:210-219.

36. Mendoza $L$, Xenarios I: A method for the generation of standardized qualitative dynamical systems of regulatory networks. Theor Biol Med Model 2006, 3:13.

37. Wittmann DM, Krumsiek J, Saez-Rodriguez J, Lauffenburger DA, Klamt S, Theis FJ: Transforming Boolean models to continuous models: methodology and application to T-cell receptor signaling. BMC Syst Biol 2009, 3:98.

38. Gammack D, Doering CR, Kirschner DE: Macrophage response to Mycobacterium tuberculosis infection. J Math Bio 2004, 48:218-242

39. Gammack D, Ganguli S, Marino S, Segovia-Juarez J, Kirschner DE: Understanding the immune response in tuberculosis using different mathematical models and biological scales. SIAM journal of multiscale modeling and simulation 2005, 3:312-345.

40. Fomekong-Nanfack Y, Postma M, Kaandorp JA: Inferring Drosophila gap gene regulatory network: pattern analysis of simulated gene expression profiles and stability analysis. BMC Res Notes 2009, 2:256.

41. Harvill ET, Miller JF: Manipulating the host to study bacterial virulence. Curr Opin Microbiol 2000, 3:93-96.

42. Randall RE, Goodbourn S: Interferons and viruses: an interplay between induction, signalling, antiviral responses and virus countermeasures. J Gen Virol 2008, 89:1-47.

43. Kachalo S, Zhang R, Sontag E, Albert R, DasGupta B: NET-SYNTHESIS: a software for synthesis, inference and simplification of signal transduction networks. Bioinformatics 2008, 24:293-295.

44. Raman K, Bhat AG, Chandra N: A systems perspective of host-pathogen interactions: predicting disease outcome in tuberculosis. Mol Biosyst 6:516-530.

45. Aldridge BB, Saez-Rodriguez J, Muhlich JL, Sorger PK, Lauffenburger DA: Fuzzy logic analysis of kinase pathway crosstalk in TNF/EGF/insulin-induced signaling. PLoS Comput Biol 2009, 5:e1000340.

46. Chaves M, Sontag ED, Albert R: Methods of robustness analysis for Boolean models of gene control networks. Syst Biol (Stevenage) 2006, 153:154-167.

47. Thieffry D, Thomas R: Dynamical behaviour of biological regulatory networks-II. Immunity control in bacteriophage lambda. Bull Math Biol 1995, 57:277-297.

48. Celada F, Seiden PE: A computer model of cellular interactions in the immune system. Immunol Today 1992, 13:56-62.

49. Cohn M, Mata J: Quantitative modeling of immune responses. Immunol Rev 2007, 216:5-8.

50. Efroni S, Harel D, Cohen IR: Emergent dynamics of thymocyte development and lineage determination. PLoS Comput Biol 2007, 3:e13.

51. Meier-Schellersheim M, Xu X, Angermann B, Kunkel EJ, Jin T, Germain RN: Key role of local regulation in chemosensing revealed by a new molecular interaction-based modeling method. PLoS Comput Biol 2006, 2:e82.

52. Slepchenko BM, Schaff JC, Macara I, Loew LM: Quantitative cell biology with the Virtual Cell. Trends Cell Biol 2003, 13:570-576.

doi:10.1186/1742-4682-7-35

Cite this article as: Thakar et al: Dynamic models of immune responses: what is the ideal level of detail?. Theoretical Biology and Medical Modelling 2010 7:35.

\section{Submit your next manuscript to BioMed Central and take full advantage of:}

- Convenient online submission

- Thorough peer review

- No space constraints or color figure charges

- Immediate publication on acceptance

- Inclusion in PubMed, CAS, Scopus and Google Scholar

- Research which is freely available for redistribution 